\title{
REVIEW
}

Open Access

\section{High ligation of the inferior mesenteric artery during sigmoid colon and rectal cancer surgery increases the risk of anastomotic leakage: a meta-analysis}

Jinshui Zeng and Guoqiang Su* (D)

\begin{abstract}
Background: The ideal level of ligation of the inferior mesenteric artery (IMA) during curative resection of sigmoid colon and rectal cancer is still controversial. The aim of this meta-analysis was to examine the impact of high ligation and low ligation of the IMA on anastomotic leakage, overall morbidity, postoperative mortality, and oncological outcomes in patients undergoing surgery for sigmoid colon and rectal cancer.

Methods: PubMed, EMBASE, Web of Science, and BioMed Central databases were searched to identify relevant articles published from May 1953 to March 2018. A total of 18 articles (14 non-randomized studies and 4 randomized clinical trials) were identified. Review Manager 5.3 software was used for analysis of data. The pooled odds ratio (OR) and weighted mean difference (WMD), with 95\% Cl, were calculated using either the fixed effects model or random effects model.

Results: Of the 5917 patients included in this meta-analysis, 3652 patients underwent low ligation of the IMA and 2265 patients underwent high ligation of the IMA. Anastomotic leakage rate was $9.8 \%$ in high ligation patients vs. $7.0 \%$ in low ligation patients; the risk of anastomotic leakage was significantly higher in high ligation patients (OR $=1.33 ; 95 \%$ Cl 1.10-1.62; $P=0.004)$. What is more, overall morbidity was also significantly higher in high ligation patients $(\mathrm{OR}=1.39$; 95\% Cl, 1.05-1.68; $P=0.05)$. Postoperative mortality, number of harvested lymph nodes, overall recurrence rate, and 5-year survival rate did not differ significantly between the two groups.

Conclusion: Low ligation of the IMA during curative resection of sigmoid colon and rectal cancer appears to be associated with lower risk of anastomotic leakage and overall morbidity. However, there was no significant advantage of low ligation over high ligation of IMA in terms of postoperative mortality, the number of harvested lymph nodes, overall recurrence rate, or 5-year survival rate.
\end{abstract}

Keywords: Inferior mesenteric artery, High ligation, Low ligation, Sigmoid colon cancer, Rectal cancer, Anastomotic leakage

\footnotetext{
* Correspondence: suguoqiang66@163.com

Department III of Gastrointestinal Surgery, First Affiliated Hospital of Xiamen University, Xiamen 361003, Fujian, China
}

(c) The Author(s). 2018 Open Access This article is distributed under the terms of the Creative Commons Attribution 4.0 International License (http://creativecommons.org/licenses/by/4.0/), which permits unrestricted use, distribution, and reproduction in any medium, provided you give appropriate credit to the original author(s) and the source, provide a link to the Creative Commons license, and indicate if changes were made. The Creative Commons Public Domain Dedication waiver (http://creativecommons.org/publicdomain/zero/1.0/) applies to the data made available in this article, unless otherwise stated. 


\section{Background}

Colorectal cancer (CRC) is the third most common cancer in the world and the fourth most common cause of cancer-related death [1]. The standard operative procedure for curative resection of rectal cancer and sigmoid colon cancer includes removal of the tumor, wide resection of the colonic mesentery, and ligation of inferior mesenteric vessels [2]. There are two options for ligation of the inferior mesenteric artery (IMA): (1) high ligation, with ligation of the left colic artery (LCA), and (2) low ligation, with preservation of the LCA [3]. Ever since 1908, when Miles et al. recommended low ligation of the IMA [4] and Moynihan et al. recommended high ligation of the IMA [5], the controversy over the level of ligation of the IMA has persisted.

Lymph node metastasis is a crucial factor affecting the outcome of sigmoid colon and rectal cancer surgery [6], and ligation of the IMA root can facilitate removal of the surrounding lymph nodes during curative resection of sigmoid colon and rectal cancer. Thus, the high ligation of the IMA can improve lymph node retrieval rates and enable accurate tumor staging [7]. However, it is uncertain whether there are long-term survival benefits to be had with high ligation [8-10]. Seike et al. reported significant reduction in blood flow to the anastomosis after high ligation of the IMA [11]. Others have argued that high ligation is associated with higher risk of hypogastric plexus injury, whereas low ligation avoids damage to the pre-aortic nerves and preserves the blood supply to the anastomosis [12, 13]. Meanwhile, several clinical studies have demonstrated that high ligation allows complete mobilization of the proximal colonic limb and thus helps reduce anastomotic tension [14]. Interestingly, previous meta-analyses have arrived at different conclusions about the incidence of anastomotic leakage (AL) with the two approaches. Fan et al. reported that low ligation of the IMA may lower the risk of AL, whereas pooled data from the studies of Cirocchi et al. and Yang et al. showed that there was no significant difference in the incidence of AL with the two approaches $[5,8,9]$.

This meta-analysis was performed to compare the effect of high versus low ligation of the IMA during curative resection of sigmoid colon and rectal cancer on outcomes such as AL, overall morbidity, postoperative mortality, recurrence, and survival.

\section{Methods}

\section{Study selection}

This meta-analysis was conducted in March 2018. We searched the databases of PubMed, EMBASE, Web of Science, and BioMed Central for all articles referring to high and low ligation of the IMA during curative resection of sigmoid colon and rectal cancer. The following MeSH terms were used for the search: "inferior mesenteric artery," "left colic artery," "colorectal cancer," "high ligation," "low ligation," and "anastomotic leakage." Two authors independently reviewed and assessed the titles and/or abstracts of the studies and excluded obviously irrelevant articles. The full texts of the remaining studies were examined to decide whether they met the inclusion criteria. In addition, we manually reviewed the reference lists of potentially relevant articles to broaden the search.

\section{Inclusion criteria}

Studies were eligible if they were (1) non-randomized studies or randomized controlled trials (RCTs) comparing high ligation vs. low ligation of the IMA during curative resection of sigmoid colon and rectal cancer, regardless of the surgical approach (open or laparoscopic) and surgical procedure (elective or emergency). Articles in all languages were eligible for inclusion. In cases of duplicate articles, only the latest published version was included.

\section{Exclusion criteria}

Studies were excluded if (1) the outcome of the primary end point (AL) was not reported; (2) there was no control group; and (3) the full text could not be accessed. Review articles, letters, case reports, and meta-analyses were not considered.

\section{End points}

The primary end point was the AL rate. The secondary end points were overall morbidity, postoperative mortality, number of harvested lymph nodes, overall recurrence rate, and 5-year survival rate.

\section{Data items}

The following data were extracted from the included studies: the number of patients in each treatment group, year and country of the study, type of study (non-randomized study vs. RCT), type of surgery (high ligation vs. low ligation), study inclusion and exclusion criteria, and the outcomes measured. Relevant data were extracted by two authors independently, and any disagreement was resolved by discussion.

\section{Assessment of the quality}

The quality and bias risk of the included studies was assessed independently by two authors; disagreements were settled by discussion. The Newcastle-Ottawa Scale (NOS) [15] was used to assess the quality of non-randomized clinical studies. Studies were judged on the basis of criteria such as the quality of patient selection, ascertainment of exposure, comparability of groups, and outcomes of patients. The total NOS score 


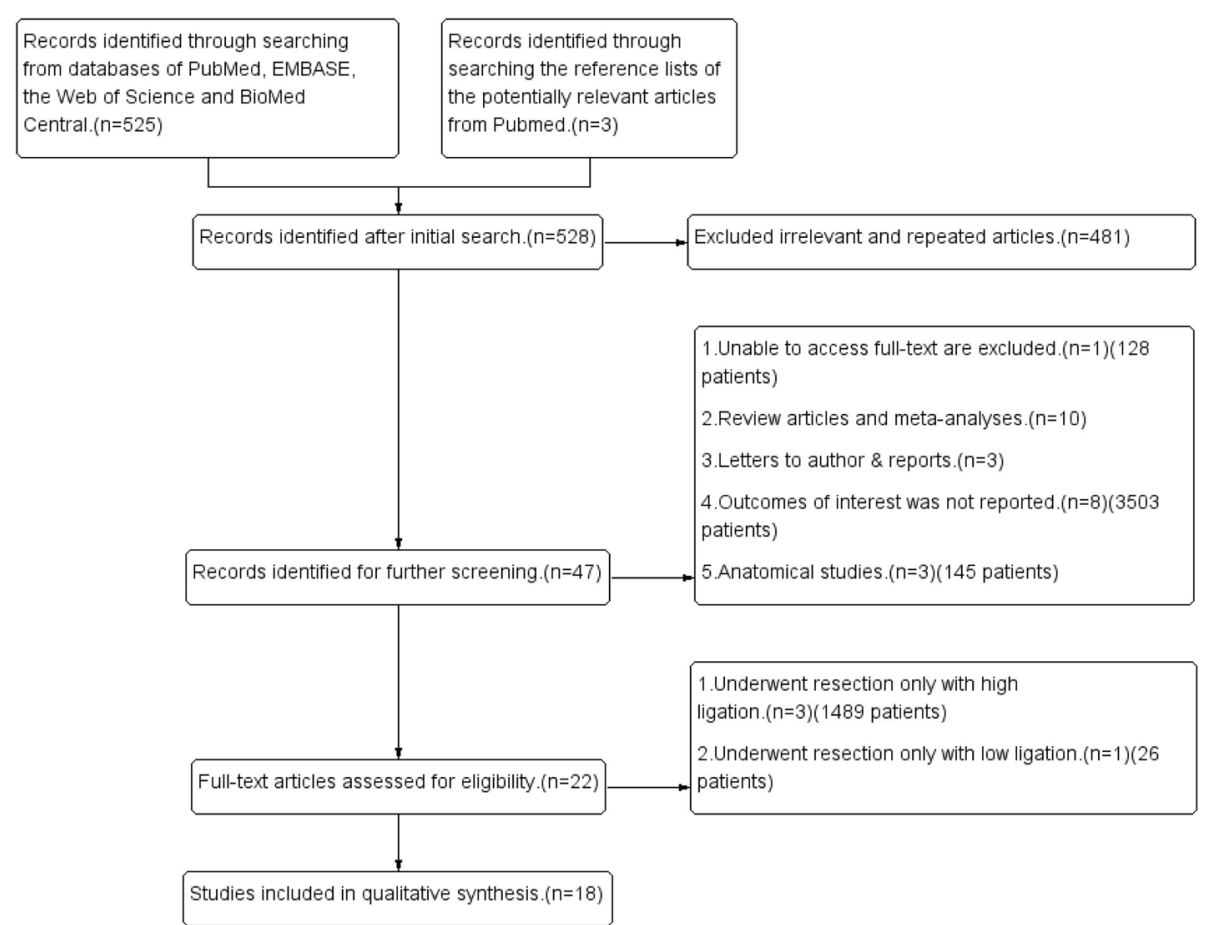

Fig. 1 Flow diagram showing the process of literature search

Table 1 Characteristics of the studies included in this meta-analysis

\begin{tabular}{|c|c|c|c|c|c|c|c|}
\hline \multirow[t]{2}{*}{ Study } & \multirow[t]{2}{*}{ Country } & \multirow[t]{2}{*}{ Year } & \multirow[t]{2}{*}{ Diagnosis } & \multirow[t]{2}{*}{ Type of surgery } & \multicolumn{2}{|c|}{$\begin{array}{l}\text { Surgical treatment of IMA } \\
\text { (no. of patients) }\end{array}$} & \multirow[t]{2}{*}{ Type of study } \\
\hline & & & & & High ligation & Low ligation & \\
\hline Corder AP & UK & 1992 & Rectal cancer & TME & 91 & 52 & Retrospective cohort \\
\hline Hall NR & UK & 1995 & Left-side colorectal cancer & Curative resection & 30 & 32 & Retrospective cohort \\
\hline Komen N & Netherlands & 2011 & Rectal cancer & TME & 16 & 17 & Retrospective cohort \\
\hline Sekimoto M & Japan & 2011 & Sigmoid and rectal cancer & Laparoscopic resection & 27 & 45 & Retrospective cohort \\
\hline Rutegard M & Sweden & 2012 & Rectal cancer & $A R$ & 818 & 1101 & Retrospective cohort \\
\hline Hinoi T & Japan & 2013 & Rectal cancer & Laparoscopic resection & 304 & 584 & Retrospective cohort \\
\hline Yamamoto M & Japan & 2014 & Sigmoid and rectal cancer & Laparoscopic resection & 91 & 120 & Retrospective cohort \\
\hline Bostrm P & Sweden & 2015 & Rectal cancer & AR & 334 & 388 & Retrospective cohort \\
\hline Matsuda K & Japan & 2015 & Rectal cancer & $A R$ & 51 & 49 & RCT \\
\hline Huang J & China & 2016 & Rectal cancer & Laparoscopic resection & 87 & 29 & Retrospective cohort \\
\hline Niu JW & China & 2016 & Rectal cancer & Laparoscopic AR & 45 & 52 & RCT \\
\hline Rutegard M & Japan & 2016 & Rectal cancer & $A R$ & 5 & 18 & Retrospective cohort \\
\hline Yasuda K & Japan & 2016 & Colorectal cancer & Curative resection & 42 & 147 & Retrospective cohort \\
\hline Zhang LY & China & 2016 & Rectal cancer & Laparoscopic resection & 42 & 61 & Retrospective cohort \\
\hline Zhang YD & China & 2016 & Rectal cancer & Laparoscopic LAR & 84 & 132 & Retrospective cohort \\
\hline Guo YC & China & 2017 & Rectal cancer & Radical resection & 29 & 28 & RCT \\
\hline Mihara $Y$ & Japan & 2017 & Colorectal cancer & NA & 117 & 745 & Retrospective cohort \\
\hline Zhou JM & China & 2018 & Rectal cancer & Laparoscopic resection & 52 & 52 & RCT \\
\hline
\end{tabular}

TME total mesorectal excision, $A R$ anterior resection, $L A R$ low anterior resection, NA not available, $R C T$ randomized clinical trial 
Table 2 Quality of non-randomized studies as assessed by the Newcastle-Ottawa Scale

\begin{tabular}{|c|c|c|c|c|c|c|c|c|c|c|}
\hline \multirow[t]{3}{*}{ Study } & \multirow[t]{3}{*}{ Year } & \multicolumn{4}{|c|}{ Selection } & \multirow{3}{*}{$\begin{array}{l}\text { Comparability } \\
1 \\
(\operatorname{Max} 2)\end{array}$} & \multicolumn{3}{|c|}{ Outcome } & \multirow{3}{*}{$\begin{array}{l}\text { Score } \\
\text { (Max 9) }\end{array}$} \\
\hline & & 1 & 2 & 3 & 4 & & 1 & 2 & 3 & \\
\hline & & $(\operatorname{Max} 1)$ & $(\operatorname{Max} 1)$ & (Max 1) & $(\operatorname{Max} 1)$ & & (Max 1) & (Max 1) & (Max 1) & \\
\hline Corder AP & 1992 & * & * & $*$ & * & * & * & - & $*$ & 7 \\
\hline Hall NR & 1995 & * & * & * & * & $* *$ & * & - & - & 7 \\
\hline Komen N & 2011 & * & * & * & * & * & * & * & * & 8 \\
\hline Sekimoto M & 2011 & $*$ & * & * & * & * & * & - & * & 7 \\
\hline Rutegard M & 2012 & * & * & * & * & * & * & * & * & 8 \\
\hline Hinoi T & 2013 & * & * & * & * & $* *$ & * & * & - & 8 \\
\hline Yamamoto M & 2014 & * & * & * & * & * & * & * & * & 8 \\
\hline Bostrm P & 2015 & * & * & * & * & * & * & * & * & 8 \\
\hline Huang J & 2016 & * & * & * & * & $* *$ & * & * & * & 9 \\
\hline Rutegard M & 2016 & * & $*$ & * & * & * & * & * & * & 8 \\
\hline Yasuda K & 2016 & * & $*$ & * & * & * & * & * & * & 8 \\
\hline Zhang LY & 2016 & * & * & * & * & $* *$ & * & * & * & 9 \\
\hline Zhang YD & 2016 & * & $*$ & * & * & $* *$ & * & * & * & 9 \\
\hline Mihara Y & 2017 & * & * & * & * & * & * & * & * & 8 \\
\hline
\end{tabular}

Each "*" indicates one point for each item of the Newcastle -Ottawa Scale

ranges from 0 to 9 stars; a score of $\geq 6$ stars indicates high quality. The Jadad scoring system [16] was used to assess the bias risk of the RCTs. This scoring system is based on three specific items: randomization, blinding, and withdrawals and dropouts. The total score ranges from 0 to 5 ; a score of $\leq 2$ indicates poor-quality evidence and a score of $\geq 3$ indicates high-quality evidence.

\section{Statistical analysis}

Statistical analysis was performed using the statistical software Review Manager Version 5.3 (Copenhagen: The Nordic Cochrane Centre, the Cochrane Collaboration, 2014). The odds ratios (OR) and the weighted mean differences (WMD), with 95\% confidence intervals (CIs), were calculated for dichotomous and continuous variables, respectively. Homogeneity among the studies was assessed using the chi-square test and the inconsistency statistics $\left(I^{2}\right)$. Statistically significant homogeneity was indicated by a chi-square test with $P<0.10$ [17]. In addition, $I^{2}>25 \%, I^{2}>50 \%$, and $I^{2}>75 \%$ indicated low, moderate, and high heterogeneity, respectively [18]. When there was no heterogeneity among the studies, the Mantel-Haenszel method was adopted to be combined with the ORs or the inverse variance method was used to be combined with the WMDs for a fixed effects model $[19,20]$. If there was heterogeneity, the random effects model was adopted for the pooled analysis (DerSimonian and Laird method) [21]. The $Z$ test (and the related $P$ value) was used to assess overall effect. Statistical significance was at $P \leq 0.05$.
Sensitivity analysis was performed to explore statistical heterogeneity. Publication bias was assessed with funnel plots.

\section{Results}

\section{Description of the studies}

Figure 1 shows the process of study selection for this meta-analysis. A total of 18 articles [22-39] published between July 1992 and March 2018 were included for this meta-analysis (Table 1). They included 14 non-randomized studies [22-29, 31, 33-36, 38] and 4 RCTs [30, 32, 37, 39]. The total number of patients was 5917, which included 3652 patients who underwent low ligation of the IMA and 2265 patients who underwent high ligation.

Table 2 shows the results of quality assessment of the non-randomized studies with NOS. Table 3 shows the results of bias risk assessment of the RCTs with the Jadad scoring system. Table 4 lists the outcomes of interest reported in patients receiving high and low ligation of the IMA.

Table 3 Bias risk in the randomized controlled trials (RCTs) as assessed by the Jadad scoring system

\begin{tabular}{llllll}
\hline Studies & Year & Randomization & Blinding & $\begin{array}{l}\text { Withdrawals } \\
\text { and dropouts }\end{array}$ & Total \\
\hline Matsuda K & 2015 & 2 & 1 & 1 & 4 \\
Niu JW & 2016 & 1 & 0 & 1 & 2 \\
Guo YC & 2017 & 2 & 1 & 1 & 4 \\
Zhou JM & 2018 & 1 & 0 & 1 & 2 \\
\hline
\end{tabular}


Table 4 Outcomes of interest reported in the 18 studies in patients receiving high or low ligation of the IMA

\begin{tabular}{|c|c|c|c|c|c|c|c|c|c|c|c|c|c|c|c|}
\hline \multirow[t]{2}{*}{ Study } & \multirow[t]{2}{*}{ Year } & \multicolumn{2}{|c|}{$\begin{array}{l}\text { Surgical treatment } \\
\text { of IMA (no. of patients) }\end{array}$} & \multicolumn{2}{|c|}{$\begin{array}{l}\text { Anastomotic leakage } \\
\text { (no. of patients) }\end{array}$} & \multicolumn{2}{|c|}{$\begin{array}{l}\text { Overall } \\
\text { morbidity (\%) }\end{array}$} & \multicolumn{2}{|c|}{$\begin{array}{l}\text { Postoperative } \\
\text { mortality (\%) }\end{array}$} & \multicolumn{2}{|c|}{$\begin{array}{l}\text { Lymph nodes } \\
\text { harvested (mean) }\end{array}$} & \multicolumn{2}{|c|}{$\begin{array}{l}\text { Overall recurrence } \\
\text { rate }(\%)\end{array}$} & \multicolumn{2}{|c|}{$\begin{array}{l}5 \text {-year survival } \\
\text { rate (\%) }\end{array}$} \\
\hline & & $\begin{array}{l}\text { High } \\
\text { ligation }\end{array}$ & $\begin{array}{l}\text { Low } \\
\text { ligation }\end{array}$ & $\begin{array}{l}\text { High } \\
\text { ligation }\end{array}$ & $\begin{array}{l}\text { Low } \\
\text { ligation }\end{array}$ & $\begin{array}{l}\text { High } \\
\text { ligation }\end{array}$ & $\begin{array}{l}\text { Low } \\
\text { ligation }\end{array}$ & $\begin{array}{l}\text { High } \\
\text { ligation }\end{array}$ & $\begin{array}{l}\text { Low } \\
\text { ligation }\end{array}$ & $\begin{array}{l}\text { High } \\
\text { ligation }\end{array}$ & $\begin{array}{l}\text { Low } \\
\text { ligation }\end{array}$ & $\begin{array}{l}\text { High } \\
\text { ligation }\end{array}$ & $\begin{array}{l}\text { Low } \\
\text { ligation }\end{array}$ & $\begin{array}{l}\text { High } \\
\text { ligation }\end{array}$ & $\begin{array}{l}\text { Low } \\
\text { ligation }\end{array}$ \\
\hline Corder AP & 1992 & 91 & 52 & 12 & 6 & & & & & & & & & & \\
\hline Hall NR & 1995 & 30 & 32 & 4 & 2 & & & & & & & & & & \\
\hline Komen N & 2011 & 16 & 17 & 1 & 1 & & & & & & & & & & \\
\hline Sekimoto M & 2011 & 27 & 45 & 0 & 1 & & & & & & & & & & \\
\hline Rutegard M & 2012 & 818 & 1101 & 81 & 108 & & & 1.6 & 1.5 & & & & & & \\
\hline Hinoi T & 2013 & 304 & 584 & 40 & 43 & 22.7 & 22.3 & & & 17.8 & 13.3 & & & & \\
\hline Yamamoto M & 2014 & 91 & 120 & 2 & 2 & & & & & & & 16.5 & 15.0 & 91.2 & 90.0 \\
\hline Bostrm P & 2015 & 334 & 388 & 41 & 41 & & & 2.7 & 1.8 & & & & & & \\
\hline Matsuda K & 2015 & 51 & 49 & 8 & 5 & 35.3 & 20.4 & & & & & 1.96 & 2.0 & & \\
\hline Huang J & 2016 & 87 & 29 & 7 & 1 & & & & & & & & & & \\
\hline Niu JW & 2016 & 45 & 52 & 3 & 0 & & & & & & & & & & \\
\hline Rutegard M & 2016 & 5 & 18 & 1 & 2 & & & & & & & & & & \\
\hline Yasuda K & 2016 & 42 & 147 & 2 & 3 & 19.1 & 17.0 & & & & & 23.8 & 20.4 & 82.4 & 80.3 \\
\hline Zhang LY & 2016 & 42 & 61 & 3 & 2 & & & & & 16.1 & 15.5 & & & & \\
\hline Zhang YD & 2016 & 84 & 132 & 2 & 0 & & & & & 14.9 & 14.3 & & & & \\
\hline Guo YC & 2017 & 29 & 28 & 3 & 1 & & & & & & & & & & \\
\hline Mihara Y & 2017 & 117 & 745 & 9 & 35 & 53.0 & 38.5 & & & 16.21 & 17.71 & & & & \\
\hline Zhou JM & 2018 & 52 & 52 & 2 & 0 & 5.8 & 9.6 & & & 16.9 & 24.9 & & & & \\
\hline
\end{tabular}

Meta-analysis of the primary end point

The pooled AL rate was $9.8 \%(221 / 2265)$ in the high ligation group and $7.0 \%(254 / 3652)$ in the low ligation group. The risk of AL was significantly greater in the high ligation group (OR, 1.33; 95\% CI, 1.10-1.62; $P=0.004$ ), without heterogeneity among the studies $\left(\chi^{2}=11.22\right.$, $I^{2}=0 \%$; Fig. 2).

In the 14 non-randomized clinical studies, the $\mathrm{AL}$ rate was $9.8 \%(205 / 2088)$ in the high ligation group and $7.1 \%(248 / 3471)$ in the low ligation group. The

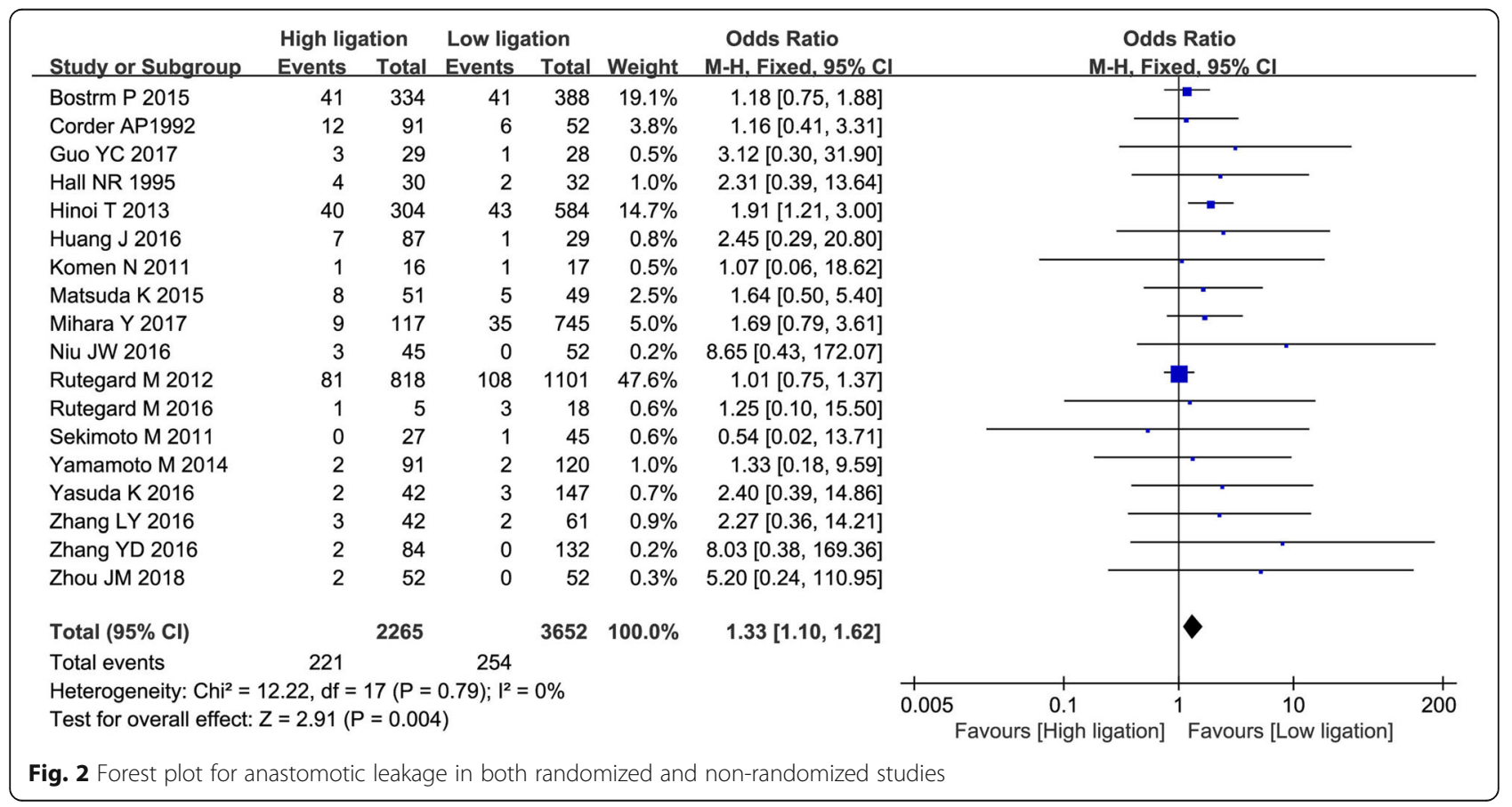




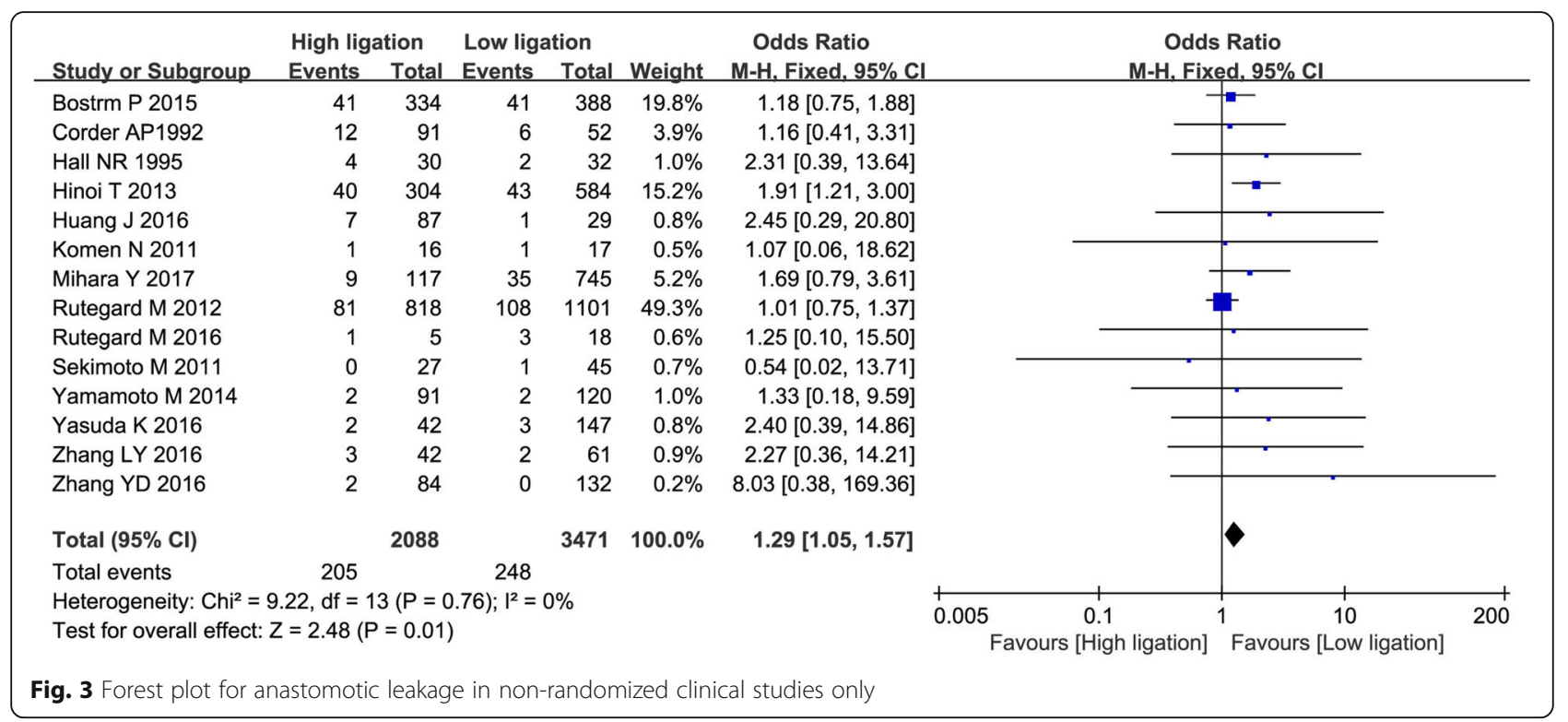

risk of AL was significantly higher in the high ligation group $(\mathrm{OR}=1.29 ; 95 \% \mathrm{CI}, 1.05-1.57 ; P=0.01)$, without heterogeneity between the studies $\left(\chi^{2}=9.22 ; I^{2}=0 \%\right.$; Fig. 3).

In the four included RCTs, the risk of $\mathrm{AL}$ showed no heterogeneity between studies $\left(\chi^{2}=1.42 ; I^{2}=0 \%\right)$, and so a fixed effects model was adopted for the analysis. The AL rates were $9.0 \%(16 / 177)$ in the high ligation group and $3.3 \%(6 / 181)$ in the low ligation group. The risk of AL was significantly higher in the high ligation group $(\mathrm{OR}=2.63 ; 95 \% \mathrm{CI}, 1.05-6.59$; $P=0.04 ;$ Fig. 4).

\section{Meta-analysis of the secondary end points}

Overall morbidity was reported in only five studies $[27,30,34,38,39]$. There was substantial heterogeneity among the studies $\left(I^{2}=32 \%, P=0.21\right)$, and so the random effects model was adopted. Pooled analysis revealed overall morbidity was significantly higher in high ligation patients $(\mathrm{OR}=1.39$; 95\% CI, 1.05-1.68; $P=0.05$; Fig. 5).

Two studies [26, 29] reported postoperative mortality. There was no heterogeneity among the studies $\left(\chi^{2}=0.25\right.$; $\left.I^{2}=0 \%\right)$. The difference in postoperative mortality between the high ligation and low ligation groups was not statistically significant $(\mathrm{OR}=1.23 ; 95 \% \mathrm{CI}, 0.68-2.21$; $P=0.50$; Fig. 6).

Five studies [27, 35-37, 39] compared the number of harvested lymph nodes. There was substantial heterogeneity among the studies $\left(I^{2}=97 \%\right)$, and so the random effects model was adopted. Pooled analysis showed no statistically significant difference between the high ligation group and the low ligation group (OR $=-0.72 ; 95 \%$ CI, $-3.57-2.12 ; P=0.62$; Fig. 7 ).

The overall recurrence rate was reported in three studies $[28,30,34]$. There was no heterogeneity among

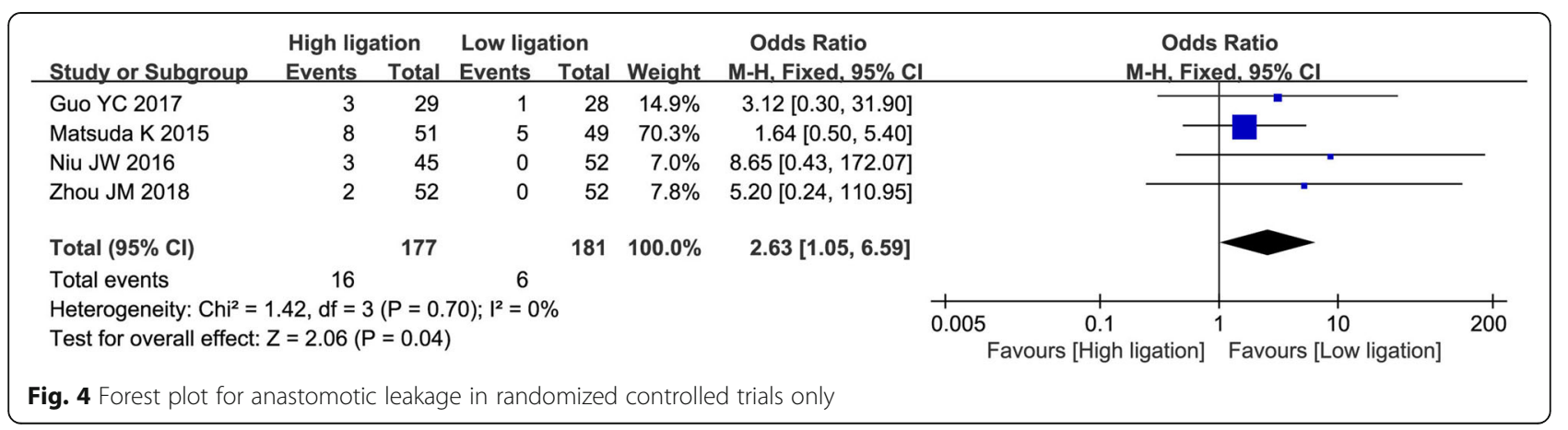




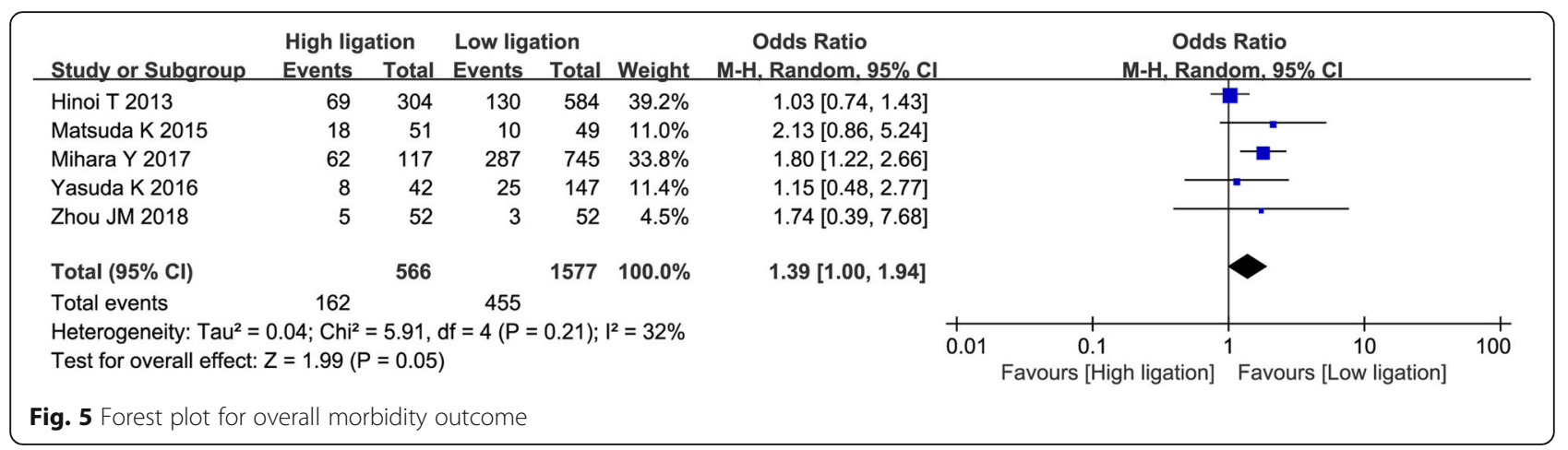

the studies $\left(\chi^{2}=0.04 ; I^{2}=0 \%\right)$, and so a fixed effects model was used. There was no significant difference in overall recurrence rate between the high ligation group and the low ligation group $(\mathrm{OR}=1.15 ; 95 \% \mathrm{CI}, 0.67-1.98$; $P=0.60$; Fig. 8).

Two studies [28, 34] assessed the 5-year survival rate. There was no heterogeneity among the studies $\left(\chi^{2}=0.01 ; I^{2}=0 \%\right)$. Pooled analysis showed no significant difference in the 5 -year survival rate between the high ligation group and low ligation group $(\mathrm{OR}=1.19$; 95\% CI, 0.62-2.29; $P=0.60$; Fig. 9).

\section{Sensitivity analysis}

On NOS assessment, the 14 non-randomized studies showed high quality. However, the Jadad score was low for the studies of Niu et al. [32] and Zhou et al. [39] (Table 3). They did not describe the exact procedure of blinding, considering that the outcome analyzed in this study was AL. We excluded the studies with low Jadad score and recalculated the pooled OR for the primary end point (AL) in the remaining studies. However, in both non-randomized and randomized studies, the risk of AL remained higher in high ligation patients. Due to the low number of studies reporting the secondary end points, pooled sensitivity analysis for the secondary end points was not performed.

\section{Publication bias}

No significant publication bias was detected. As the funnel plot (Fig. 10) shows, the ORs of all the studies were within the pooled $95 \%$ confidence intervals. In addition, the studies were equally distributed on both sides of the vertical line.

\section{Discussion}

In CRC surgery, $\mathrm{AL}$ is the most common serious postoperative complication and an important cause of mortality. It is still not certain whether high or low ligation of the IMA is better for reducing the risk of AL. The primary aim of this meta-analysis was to examine how the level of IMA ligation was associated with the risk of AL. Factors reported to be associated with AL [40] include anastomosis tension, hemorrhage, hypoalbuminemia, blood transfusion, operative field infection, longer operation time, and corticosteroid use.

Anastomotic ischemia and increased anastomosis tension are believed to be the major reasons for the development of AL [14, 41]. High ligation of the IMA is often indispensable to achieve a tension-free anastomosis during low anterior resection, and undoubtedly, blood supply is a crucial factor for the healing of colorectal anastomoses. Some surgeons believe that the

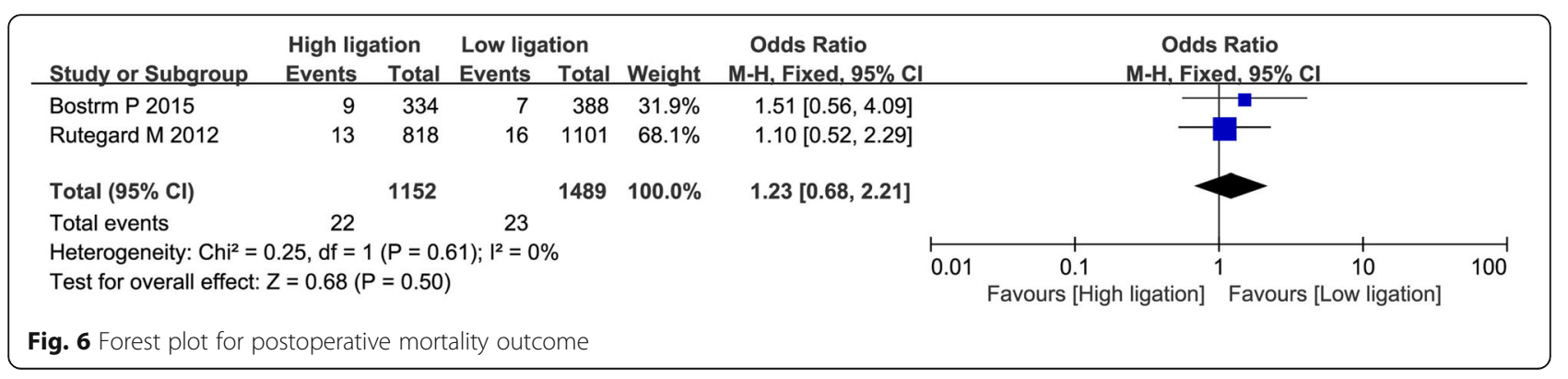




\begin{tabular}{|c|c|c|c|c|c|c|c|c|c|c|}
\hline \multirow[b]{2}{*}{ Study or Subgroup } & \multicolumn{3}{|c|}{ High ligation } & \multicolumn{3}{|c|}{ Low ligation } & \multirow[b]{2}{*}{ Weight } & \multirow{2}{*}{$\begin{array}{l}\text { Mean Difference } \\
\text { IV, Random, } 95 \% \mathrm{Cl}\end{array}$} & \multirow{2}{*}{\multicolumn{2}{|c|}{$\begin{array}{c}\text { Mean Difference } \\
\text { IV. Random, } 95 \% \mathrm{Cl}\end{array}$}} \\
\hline & Mean & SD & Total & Mean & SD & Total & & & & \\
\hline Guo YC 2017 & 16.21 & 1.08 & 29 & 17.71 & 1.36 & 28 & $21.2 \%$ & $-1.50[-2.14,-0.86]$ & $-=$ & \\
\hline Hinoi T 2013 & 17.8 & 10.1 & 304 & 13.3 & 8.1 & 584 & $20.5 \%$ & $4.50[3.19,5.81]$ & & $\because-$ \\
\hline Zhang LY 2016 & 16.1 & 6.8 & 42 & 15.5 & 7.2 & 61 & $17.8 \%$ & $0.60[-2.14,3.34]$ & & \\
\hline Zhang YD 2016 & 14.9 & 2.9 & 84 & 14.3 & 2.4 & 132 & $21.1 \%$ & $0.60[-0.14,1.34]$ & & - \\
\hline Zhou JM 2018 & 16.9 & 4.2 & 52 & 24.9 & 5.7 & 52 & $19.5 \%$ & $-8.00[-9.92,-6.08]$ & & \\
\hline Total $(95 \% \mathrm{Cl})$ & & & 511 & & & 857 & $100.0 \%$ & $-0.72[-3.57,2.12]$ & & \\
\hline $\begin{array}{l}\text { Heterogeneity: } \mathrm{Tau}^{2}= \\
\text { Test for overall effect: }\end{array}$ & $\begin{array}{l}9.85 ; \mathrm{Ch} \\
z=0.50\end{array}$ & $\begin{array}{l}i^{2}=13 \\
(P=0\end{array}$ & $\begin{array}{l}2.37, \mathrm{df} \\
62)\end{array}$ & $f=4(P$ & $<0.00$ & 01); I & $2^{2}=97 \%$ & & $\begin{array}{ccc}-10 & -5 & 0 \\
\text { Favours [High ligation] }\end{array}$ & $\begin{array}{cc}5 & 10 \\
\text { Favours [Low ligation] }\end{array}$ \\
\hline
\end{tabular}

marginal arteries are sufficient to guarantee adequate blood supply to the anastomosis in patients receiving high ligation of the IMA $[42,43]$, whereas others argue that LCA ligation would reduce blood supply to the proximal limb [11, 23, 24, 44]. In 2012, Bonnet et al. performed an anatomical study to examine how high and low ligation of the IMA affected colon length in CRC surgery and concluded that the remnant colon was $10 \mathrm{~cm}$ longer when high ligation was performed [45]. However, in another anatomical study, Buunen et al. found that low ligation provided sufficient remnant colon length to guarantee a tension-free anastomosis in $80 \%$ of their specimens [46]. Komen et al. [24] used laser Doppler flowmetry to compare colonic perfusion after high or low ligation of the IMA in rectal surgery and reported that the blood flow ratio was higher when patients received low ligation, suggesting that the anastomosis might benefit from low ligation of the IMA. A prospective cohort study conducted by Hinoi et al. [27] in 2013 showed that LCA preservation (i.e., low ligation of the IMA) in laparoscopic anterior resection for middle and low rectal cancer was associated with a lower AL rate.

Some recently published meta-analyses [5, 8-10] that compared outcomes after CRC surgery found no statistically significant differences between high ligation patients and low ligation patients in 5-year survival rate, lymph node yield, postoperative morbidity, postoperative mortality, overall recurrence rate, incidence of bowel obstruction, intraoperative blood loss, operation time, surgical site infection, postoperative bleeding, and so on. However, the AL rate differed between the two sets of patients. Fan et al. [9] analyzed the division branches of the IMA in sigmoid colon and rectal cancer surgery and concluded that low ligation of the IMA may be less likely to cause AL. Cirocchi et al. and Yang et al. $[5,8]$ analyzed high tie and low tie of the IMA in CRC surgery and showed that there was no significant difference between the two approaches. It should be noted that Cirocchi et al. and Yang et al. had a fewer number of studies with data on AL than did Fan et al., and so their results may be less reliable. We included both randomized and non-randomized studies in our meta-analysis and found that low ligation of the IMA in sigmoid colon and rectal cancer surgery could significantly reduce the AL rate $(P=$ 0.004). Analysis of data from non-randomized studies and RCTs separately also showed that high ligation was associated with higher risk of $\mathrm{AL}(P=0.01$ and $P=$ 0.04, respectively). Unfortunately, the number of RCTs in our meta-analysis was small and a lack of the data on the incidence of anastomotic leakage in the RCTs. Furthermore, there were obvious limitations in the data available. Most of the data were from non-randomized

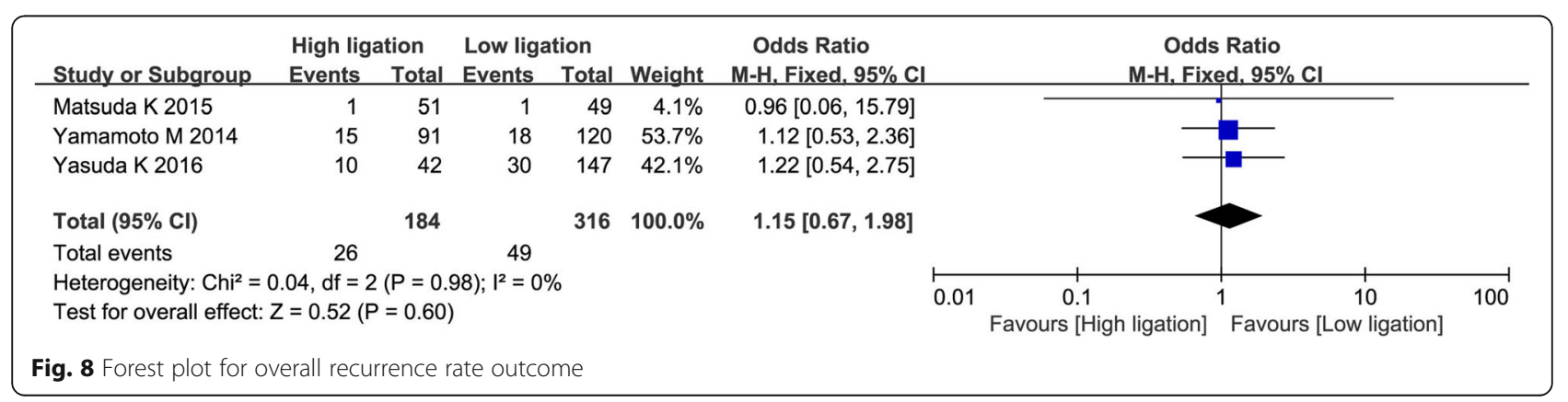




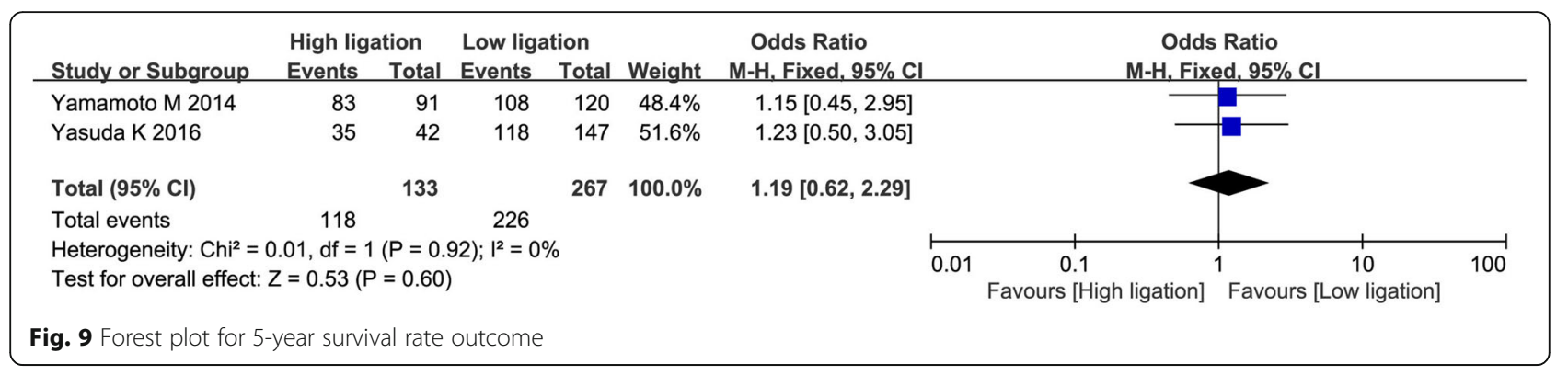

clinical studies performed over a decade ago, and it is likely that there were many differences in the management of sigmoid colon and rectal cancer over this period.

We found no significant differences between high ligation and low ligation patients in postoperative mortality, number of harvested lymph nodes, overall recurrence rate, and 5-year survival rate. This is consistent with previous meta-analyses. We found higher incidence of overall morbidity in high ligation patients; higher incidence of AL is probably the major reason. Although it is to be expected that higher incidence of AL will also increase postoperative mortality, we did not find any significant increase in this outcome in the high ligation group. This may have been because of the small number of studies and incomplete reporting of this outcome. Several authors have reported that low ligation of the IMA in CRC surgery is associated with decrease in the number of harvested lymph nodes [47, 48]. However, we did not find a statistically significant difference between the two groups in the number of lymph nodes harvested. Furthermore, in both groups, the number of lymph nodes harvested was $>12$, which meets the recommendation in the National Comprehensive Cancer Network guidelines [49]. Some authors have reported that AL after CRC surgery is associated with cancer recurrence and poor prognosis [50]. We did not find any association between level of ligation and survival or recurrence after CRC, but this too may have been because of the small number of included studies and the lack of relevant data in the four RCTs in this meta-analysis.

\section{Conclusions}

Low IMA ligation during curative resection of sigmoid colon and rectal cancer appears to be associated with relatively higher risk of AL and overall morbidity. However, postoperative mortality, number of harvested lymph nodes, overall recurrence rate, and 5-year survival rate do not seem to be affected by the level of ligation. Large well-designed multicenter randomized clinical trials are necessary to confirm these findings and throw more light on this topic.

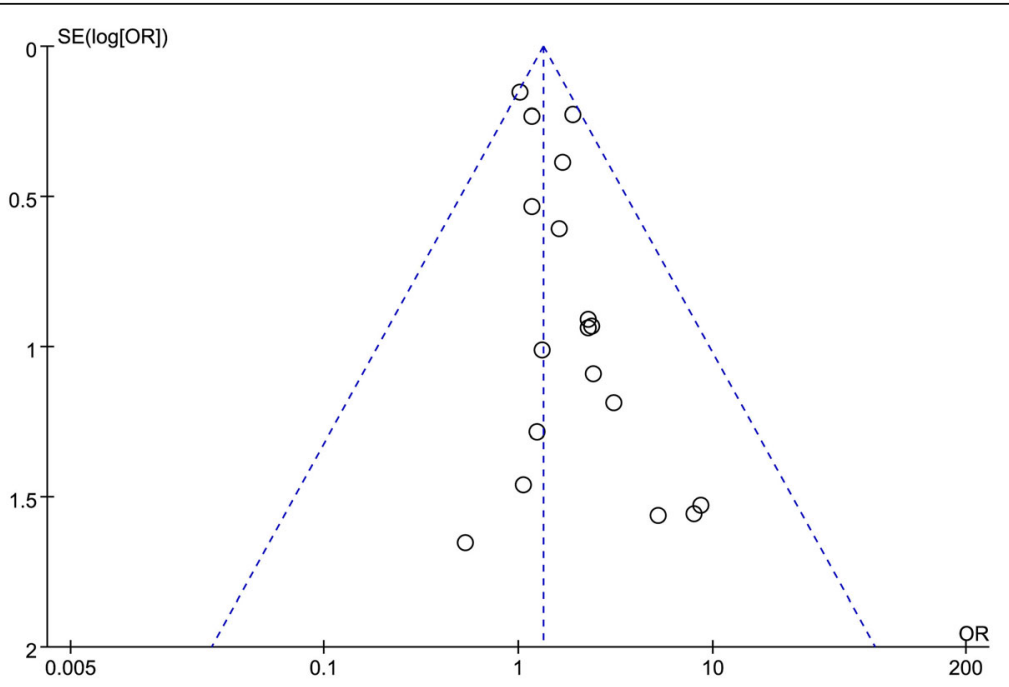

Fig. 10 Funnel plot of anastomotic leakage 


\section{Abbreviations}

AL: Anastomotic leakage; Cl: Confidence interval; CRC: Colorectal cancer; IMA: Inferior mesenteric artery; LCA: Left colic artery; NOS: Newcastle-Ottawa Scale; OR: Odds ratio; RCT: Randomized controlled trial; WMD: Weighted mean difference

\section{Acknowledgements}

We thank the authors of the studies included in this meta-analysis.

\section{Funding}

This study was supported by a grant from the Science and Technology Planning Projects of Xiamen Science \& Technology (3502Z20154008), the Natural Science Foundation of Fujian Province, China (2015J01548), and the Science and Technology Planning \& Guidance Projects of Xiamen Health and Family Planning Commission (3502Z20149004).

\section{Availability of data and materials}

The data sets generated and/or analyzed during the current study are available in the PubMed, EMBASE, BioMed, and the Web of Science Central repository.

\section{Authors' contributions}

GS contributed to the study design. JZ and GS carried out the data collection and selection. JZ carried out the data analysis and writing. Both authors read and approved the final manuscript.

\section{Ethics approval and consent to participate}

Not applicable.

\section{Consent for publication}

Not applicable.

\section{Competing interests}

The authors declare that they have no competing interests.

\section{Publisher's Note}

Springer Nature remains neutral with regard to jurisdictional claims in published maps and institutional affiliations.

\section{Received: 22 April 2018 Accepted: 26 July 2018}

Published online: 02 August 2018

\section{References}

1. Favoriti $P$, et al. Worldwide burden of colorectal cancer: a review. Updat Surg. 2016;68(1):7-11.

2. Guraya SY. Optimum level of inferior mesenteric artery ligation for the leftsided colorectal cancer. Systematic review for high and low ligation continuum. Saudi Med J. 2016:37(7):731-6.

3. Lowry AC, et al. Consensus statement of definitions for anorectal physiology and rectal cancer. Color Dis. 2001:3(4):272-5.

4. Miles WE. A method of performing abdomino-perineal excision for carcinoma of the rectum and of the terminal portion of the pelvic colon (1908). CA Cancer J Clin. 1971;21(6):361-4.

5. Cirocchi $R$, et al. High tie versus low tie of the inferior mesenteric artery in colorectal cancer: a RCT is needed. Surg Oncol. 2012;21(3):e111-23.

6. Wakahara T, et al. Comparison of laparoscopic sigmoidectomy with and without preservation of the superior rectal artery: a single-institution retrospective study. Asian J Endosc Surg. 2015;8(1):29-33.

7. Titu LV, Tweedle E, Rooney PS. High tie of the inferior mesenteric artery in curative surgery for left colonic and rectal cancers: a systematic review. Dig Surg. 2008;25(2):148-57.

8. Yang $Y$, et al. High tie versus low tie of the inferior mesenteric artery in colorectal cancer: a meta-analysis. Int J Surg. 2018;52:20-4.

9. Fan $\mathrm{YC}$, et al. Preservation versus non-preservation of left colic artery in sigmoid and rectal cancer surgery: a meta-analysis. Int J Surg. 2018;52:269-77.

10. Singh $D$, et al. The long-term survival benefits of high and low ligation of inferior mesenteric artery in colorectal cancer surgery: a review and metaanalysis. Medicine (Baltimore). 2017:96(47):e8520.

11. Seike $K$, et al. Laser Doppler assessment of the influence of division at the root of the inferior mesenteric artery on anastomotic blood flow in rectosigmoid cancer surgery. Int J Color Dis. 2007;22(6):689-97.
12. Matsuda $\mathrm{K}$, et al. Oncological outcomes following rectal cancer surgery with high or low ligation of the inferior mesenteric artery. Gastrointest Tumors. 2017;4(1-2):45-52

13. Lange $M M$, et al. Level of arterial ligation in rectal cancer surgery: low tie preferred over high tie. A review. Dis Colon Rectum. 2008;51(7):1139-45.

14. Nano $M$, et al. Ligation of the inferior mesenteric artery in the surgery of rectal cancer: anatomical considerations. Dig Surg. 2004;21(2):123-6. discussion 126-7

15. Stang A. Critical evaluation of the Newcastle-Ottawa scale for the assessment of the quality of nonrandomized studies in meta-analyses. Eur J Epidemiol. 2010:25(9):603-5

16. Jadad $A R$, et al. Assessing the quality of reports of randomized clinical trials: is blinding necessary? Control Clin Trials. 1996;17(1):1-12.

17. Petitti DB. Approaches to heterogeneity in meta-analysis. Stat Med. 2001; 20(23):3625-33.

18. Higgins JP, et al. Measuring inconsistency in meta-analyses. BMJ. 2003; 327(7414):557-60.

19. Greenland S, Robins JM. Estimation of a common effect parameter from sparse follow-up data. Biometrics. 1985:41(1):55-68.

20. Mantel N, Haenszel W. Statistical aspects of the analysis of data from retrospective studies of disease. J Natl Cancer Inst. 1959;22(4):719-48.

21. DerSimonian R, Kacker R. Random-effects model for meta-analysis of clinical trials: an update. Contemp Clin Trials. 2007:28(2):105-14.

22. Corder AP, et al. Flush aortic tie versus selective preservation of the ascending left colic artery in low anterior resection for rectal carcinoma. Br J Surg. 1992;79(7):680-2.

23. Hall NR, et al. High tie of the inferior mesenteric artery in distal colorectal resections--a safe vascular procedure. Int J Color Dis. 1995;10(1):29-32.

24. Komen $\mathrm{N}$, et al. High tie versus low tie in rectal surgery: comparison of anastomotic perfusion. Int J Color Dis. 2011;26(8):1075-8.

25. Sekimoto $M$, et al. Laparoscopic lymph node dissection around the inferior mesenteric artery with preservation of the left colic artery. Surg Endosc. 2011;25(3):861-6.

26. Rutegard $\mathrm{M}$, et al. High tie in anterior resection for rectal cancer confers no increased risk of anastomotic leakage. Br J Surg. 2012;99(1):127-32.

27. Hinoi $\mathrm{T}$, et al. Effect of left colonic artery preservation on anastomotic leakage in laparoscopic anterior resection for middle and low rectal cancer. World J Surg. 2013:37(12):2935-43.

28. Yamamoto $M$, et al. Oncological impact of laparoscopic lymphadenectomy with preservation of the left colic artery for advanced sigmoid and rectosigmoid colon cancer. Dig Surg. 2014;31(6):452-8.

29. Bostrom $P$, et al. High arterial ligation and risk of anastomotic leakage in anterior resection for rectal cancer in patients with increased cardiovascular risk. Color Dis. 2015;17(11):1018-27.

30. Matsuda K, et al. Randomized clinical trial of defaecatory function after anterior resection for rectal cancer with high versus low ligation of the inferior mesenteric artery. Br J Surg. 2015;102(5):501-8.

31. Huang J, et al. Influences of inferior mesenteric artery types and Riolan artery arcade absence on the incidence of anastomotic leakage after laparoscopic resection of rectal cancer. Zhonghua Wei Chang Wai Ke Za Zhi. 2016:19(10):1113-8.

32. Niu JW, et al. Clinical effect of preservation of the left colonic artery in laparoscopic anterior resection for rectal cancer. Zhonghua Yi Xue Za Zhi. 2016;96(44):3582-5.

33. Rutegard $M$, et al. Anterior resection for rectal cancer and visceral blood flow: an explorative study. Scand J Surg. 2016;105(2):78-83.

34. Yasuda $\mathrm{K}$, et al. Level of arterial ligation in sigmoid colon and rectal cancer surgery. World J Surg Oncol. 2016;14:99.

35. Zhang $\mathrm{L}$, et al. Preservation of left colic artery in laparoscopic radical operation for rectal cancer. Zhonghua Wei Chang Wai Ke Za Zhi. 2016;19(8):886-91.

36. Zhang YD, et al. Clinical possibility of low ligation of inferior mesenteric artery and lymph nodes dissection in laparoscopic low anterior resection. Zhonghua Yi Xue Za Zhi. 2016;96(24):1916-8.

37. Guo $Y$, et al. Marginal artery stump pressure in left colic artery-preserving rectal cancer surgery: a clinical trial. ANZ J Surg. 2017;87(7-8):576-81.

38. Mihara $Y$, et al. Resection of colorectal cancer with versus without preservation of inferior mesenteric artery. Am J Clin Oncol. 2017:40(4):381-5.

39. Zhou J, et al. Accurate low ligation of inferior mesenteric artery and root lymph node dissection according to different vascular typing in laparoscopic radical resection of rectal cancer. Zhonghua Wei Chang Wai Ke Za Zhi. 2018:21(1):46-52. 
40. Erdas $\mathrm{E}$, et al. Anastomotic leak following colorectal surgery: incidence, risk factors and treatment. Chir Ital. 2009;61(4):407-17.

41. Bruch HP, et al. Actual standards and controversies on operative technique and lymph-node dissection in colorectal cancer. Langenbeck's Arch Surg. 1999;384(2):167-75.

42. Morgan CN, Griffiths JD. High ligation of the inferior mesenteric artery during operations for carcinoma of the distal colon and rectum. Surg Gynecol Obstet. 1959;108(6):641-50.

43. Goligher JC. The adequacy of the marginal blood-supply to the left colon after high ligation of the inferior mesenteric artery during excision of the rectum. Br J Surg. 1954:41(168):351-3.

44. Pezim ME, Nicholls RJ. Survival after high or low ligation of the inferior mesenteric artery during curative surgery for rectal cancer. Ann Surg. 1984; 200(6):729-33.

45. Bonnet $\mathrm{S}$, et al. High tie versus low tie vascular ligation of the inferior mesenteric artery in colorectal cancer surgery: impact on the gain in colon length and implications on the feasibility of anastomoses. Dis Colon Rectum. 2012;55(5):515-21.

46. Buunen $\mathrm{M}$, et al. Level of arterial ligation in total mesorectal excision (TME) an anatomical study. Int J Color Dis. 2009;24(11):1317-20.

47. Uehara $\mathrm{K}$, et al. Impact of upward lymph node dissection on survival rates in advanced lower rectal carcinoma. Dig Surg. 2007:24(5):375-81.

48. Kawamura YJ, et al. Effect of high ligation on the long-term result of patients with operable colon cancer, particularly those with limited nodal involvement. Eur J Surg. 2000;166(10):803-7.

49. Estrada M, McGill SY, Misra S. Evaluating compliance with National Comprehensive Cancer Network guidelines in management of colorectal, liver and thyroid cancer. J Am Coll Surg. 2014;219(4):E178.

50. Walker $\mathrm{KG}$, et al. Anastomotic leakage is predictive of diminished surviva after potentially curative resection for colorectal cancer. Ann Surg. 2004; 240(2):255-9.

Ready to submit your research? Choose BMC and benefit from:

- fast, convenient online submission

- thorough peer review by experienced researchers in your field

- rapid publication on acceptance

- support for research data, including large and complex data types

- gold Open Access which fosters wider collaboration and increased citations

- maximum visibility for your research: over $100 \mathrm{M}$ website views per year

At $\mathrm{BMC}$, research is always in progress.

Learn more biomedcentral.com/submissions 